\title{
"You don't do your hobby as a job": Stereotypes of Computational Labor and their Implications for CS Education
}

\author{
Brianna Dym \\ University of Colorado Boulder \\ brianna.dym@colorado.edu \\ Cole Rockwood \\ University of Colorado Boulder \\ cole.rockwood@colorado.edu
}

\author{
Namita Pasupuleti \\ University of Colorado Boulder \\ namita.pasupuleti@colorado.edu \\ Casey Fiesler
University of Colorado Boulder
casey.fiesler@colorado.edu
}

\begin{abstract}
Broadening participation in computing among underrepresented groups is important for not only increasing the workforce in computer science careers but also for ensuring that a broad range of stakeholders can contribute to technology development. However, stereotypes and stereotype threat represent a major barrier to underrepresented groups engaging with computer science education. To investigate alternative paths into computational work that sidestep the pressures of stereotypes, we interviewed 22 people working on computational projects in transformative fandom, a community centered on media remix and critique. Our participants-primarily women, people of color, and/or LGBTQ+ people-described a set of stereotypes about computing that prevented them from seeing their own highly technical work as computational. However, participants also described projects that not only taught them computing skills but also opened up alternative pathways for involvement in computer science. We draw on these findings to provide recommendations for how educators and professionals might break down stereotypes and incorrect expectations to increase underrepresented groups' involvement and confidence in computer science.
\end{abstract}

\section{CCS CONCEPTS}

- Social and professional topics $\rightarrow$ Computing education.

\section{KEYWORDS}

broadening participation in computing, stereotype threat, underrepresented groups

\section{ACM Reference Format:}

Brianna Dym, Namita Pasupuleti, Cole Rockwood, and Casey Fiesler. 2021. "You don't do your hobby as a job": Stereotypes of Computational Labor and their Implications for CS Education. In Proceedings of the 52nd ACM Technical Symposium on Computer Science Education (SIGCSE '21), March 13-20, 2021, Virtual Event, USA. ACM, New York, NY, USA, 7 pages. https: //doi.org/10.1145/3408877.3432396

Permission to make digital or hard copies of all or part of this work for personal or classroom use is granted without fee provided that copies are not made or distributed for profit or commercial advantage and that copies bear this notice and the full citation on the first page. Copyrights for components of this work owned by others than the author(s) must be honored. Abstracting with credit is permitted. To copy otherwise, or republish, to post on servers or to redistribute to lists, requires prior specific permission and/or a fee. Request permissions from permissions@acm.org.

SIGCSE '21, March 13-20, 2021, Virtual Event, USA

(C) 2021 Copyright held by the owner/author(s). Publication rights licensed to ACM ACM ISBN 978-1-4503-8062-1/21/03 ..\$15.00

https://doi.org/10.1145/3408877.3432396

\section{INTRODUCTION}

When it comes to learning computer science, groups like women, people of color, and LGBTQ+ people are still massively underrepresented in degree programs and industry $[3,6,8]$. Prior work shows that people from these groups often avoid technical careers due to systemic issues tied to sexism, racism, and homophobia [20, 24-26]. Among those issues, stereotypes about computer science are a powerful social mechanism that can drive people away from the field. For example, stereotype threat is a well-researched phenomenon that is a situation where there is a negative stereotype about a persons' group, and they are concerned about being judged or treated negatively on the basis of the stereotype [29]. Relatedly, stereotypes around who a computer scientist is or what their interests must be also affect computer science participation [7, 32]. People associate computer science with individuals who are singularly focused, asocial, competitive, and male, thus enabling a reinforcing loop of asocial and competitive young men dominating CS [18].

Stereotypes and stereotype threat strongly influence a person's sense of who belongs in computing as a workforce. However, there is an opportunity to expand our understanding of how people perceive the labor within computer science itself. What are people's perceptions around what constitutes doing computer science? As we attempt to broaden the image of who does computer science [7], could it also be the case that stereotypes cause people to discount their own abilities in computing because it doesn't seem "computer science enough"?

After all, formal computer science spaces are not the only place where computational work happens. What might we learn from examining informal computing spaces that represent people who are traditionally underrepresented? We looked to a community with a large number of people from underrepresented groups where computational work also takes place: transformative fandom, a community centered on media remix and critique [11,12]. Through a 22 person interview study, we expand on prior work on stereotypes and broadening participation and find that many people are carrying out complex, technical work that they do not consider computational because it does not fit their internal stereotype of what "programming" or "computer science" is. Furthermore, our participants described a sense of frustration toward formal CS education experiences they had where not only the environment, but also the method of teaching, acted as a major barrier to learning.

In this article, we explore how women, LGBTQ+ people, and people of color conceptualized the technical work they do in fandom 
spaces and contrasted it with work they viewed as more computational. We focus on themes related to: (1) how people stereotype computer science as "no fun"; (2) how computer science is not views as creative and how this impacts a participant's perception of computational skills; and (3) participant expectations toward learning computer science and what it means to be knowledgeable in computing. We close with recommendations to educators for how to undo harmful stereotypes that drive underrepresented groups away from CS education.

\section{LITERATURE REVIEW}

Broadly speaking, a stereotype is a mental image that people form around ideas like identities, occupations, or places. Prior research has studied stereotypes around computer science, particularly in the context of gender, including how stereotype threat affects underrepresented groups and stereotypes about of who a computer scientist is $[7,17,18,27]$. Overwhelmingly, computer science in U.S. schools is stereotyped as a masculine pursuit, partially because of media portrayals modeling computer scientists as white men whose only interest is programming [7]. The typical image of the computer scientist among students is an asocial, obsessive, and competitive white man $[7,18]$. This popular vision of who a computer scientist is contributes to underrepresented groups in computing remaining underrepresented. That is, if a person does not see their interests and values fitting in with their mental image of what makes a good computer scientist, they are more likely not to be involved in computer science, especially women [7, 32].

Aside from these social stereotypes about who computer scientists are and what their interests include, underrepresented groups are susceptible to stereotype threat, or the phenomenon of underperforming or refusing to engage to avoid confirming negative stereotypes about underrepresented groups. For example, research suggests that women and people of color seek out help less often or skip out on opportunities for fear of confirming negative stereotypes about their group [29]. Stereotype threat is so strong that reminding a student of a stereotype prior to an exam can cause them to perform worse than they might have previously [16].

In addition to stereotypes around gender and race [17, 20,30], a predominantly heterosexist climate both within industry and STEM education programs can push out LGBTQ+ individuals from pursuing computer science careers $[15,25,26]$. However, despite these challenges, there is an opportunity to broaden our understanding of how people engage with computing and learning computational skills. Prior work has shown that students categorize certain skills and knowledge as gendered, with more technical skills and knowledge mapping to more masculine stereotypes [17]. A broad survey of computer science students demonstrated that students early on in their CS curriculum are already forming damaging assumptions about professional programmers and their work practices that cause students to negatively self-assess their own progress in comparison to impossible standards [14]. The stereotypical association of "nerdiness" and single-minded obsession with coding is a strong barrier within and outside of computer science departments [7, 30]. However, prior work has demonstrated that targeted efforts to re-frame who a computer scientist is and what their interests are can help increase interest in computer science $[1,7,18]$, meaning that researchers and educators have an opportunity to redefine stereotypes and potentially undo their negative impacts. Extending beyond the classroom, home environments and family involvement can greatly increase a person's desire to learn and their self-confidence toward computer science [8, 31, 33].

Part of understanding how to best undo these stereotypes is to understand how they manifest, and what impacts they have both within and beyond classrooms. Outside of traditional learning environments, there are informal learning spaces for computational skills. One such space is transformative fandom. Transformative fandom (or "fandom") is a broad online community where people, primarily women, come together to make creative works that are transformative of original media. For example, people might write "fanfiction" of Star Trek about Kirk and Spock's off-screen adventures. Historically, fandom's creative works have also included highly technical projects, like compiling and editing digital video [9] or building online platforms [11]. Community members, nearly all women, who contributed to the development of the highly successful fanfiction archive Archive of Our Own (AO3, currently with over 2.5 million users) even learned to code through legitimate peripheral participation [12]. Fandom also includes a large number of LGBTQ+ people [10], as well as people with disabilities [4], and these groups form tight-knit communities of support that rely on one another to produce and share fan content while also advocating for different causes on behalf of their communities [2, 10, 23]. Because fandom is a site of empowerment for marginalized communities [10], it warrants a closer examination as a space where underrepresented groups learn computer science.

This research broadens our understanding of how computational labor is stereotyped, paying close attention to how people assess their own technical skills and practices by comparison. While gender plays a part in these stereotypes, our findings show that this expectation is something people from multiple different backgrounds struggle with, and that it causes people to discount their own expertise. Computational skills are viewed as unobtainable levels of expertise, something that a person must dedicate their life to memorizing, to "dream in code" as Margolis [21] put it.

\section{RESEARCH METHODS}

Over a five month period in 2020, we spoke to 22 participants about their experiences working on computational projects within and for their fandom community. We sought to understand why and how these projects happen outside of traditional computing spaces. In recruiting, we asked that participants have some experience with computational or technical projects in fandom, mentioning examples like modding videogames, designing websites, editing web pages or blogs, or producing data visualizations. Our recruitment post linked to a Google Form that interested parties could fill out, and encouraged people to respond even if they were not sure if they met the criteria.

We shared this post in several fandom-related Discord communities (with permission from server moderators) where members were likely to both be part of an underrepresented group in computing and work on computational projects-for example, gamer Discords for marginalized communities such as LGBTQ+, BIPOC (Black, Indigenous, and People Of Color), and women in games. We 
also shared the post on Twitter and Tumblr, both common social platforms for fandom. We also asked participants at the end of their interviews if they knew anyone who would be interested in talking to us. As a result, one participant with a large Tumblr following shared our post with an emphasis on recruiting BIPOC participants.

We initially responded to people who filled out the form on a first come, first serve basis, but began prioritizing people of color after the first 11 interviews because of compounding social factors that reduce their involvement in US-based computing programs [20]. Table 1 displays our participant demographics. The only demographic question participants were required to disclose was whether or not they were over 18 years of age, leading to some gaps in our demographic collection. All but two participants live in the US, with the other two living in Canada. Participant age ranged from ages 19 to 49 , with a majority of participants in their 20s. Education and career information is summarized to a close description to preserve anonymity.

With approval from our university IRB, we conducted semistructured interviews with participants [28], by voice, video, or text chat based on their preferences (and one interview in-person in February 2020). Participants were compensated $\$ 20$, and interviews lasted from 30 minutes to 2 hours, though the average interview length was typically 60 minutes. We began the interviews by asking them to either describe their introduction to fandom or their introduction to computational work depending on which came first, then asked follow-up questions about how their involvement and commitment to their computational project grew. If participants had experiences with computer science education, we asked them to talk about those, and asked them to talk about their thoughts on computer science and computational work in general.

Three of the four researchers conducted interviews, with the first author present for every interview. We continued interviews until we noticed that participants were describing mostly similar sets of experiences, and that we were able to clearly understand the significance of unique experiences described by participants [19]. Researchers met regularly after interviews to discuss what the participant had shared, and read through transcripts multiple times. The researchers collectively conducted a thematic analysis on the interview data [5], meeting regularly to discuss emerging themes across participant experiences.

Through multiple rounds of analysis, a distinct set of themes emerged tied to how participants discussed computational labor and skills needed to carry it out: (1) participants typically did not associate "fun" computational work with computer science; (2) participants spoke about how creativity or the lack of it influenced their perception of computational labor; and (3) participants often had unrealistic expectations around what it meant to learn computer science and perform competently as a computer scientist, expectations that were frequently enforced by formal education.

\subsection{Methodological Limitations}

Because we asked participants to contact us based on their involvement with computational projects, we were dependent on participants recognizing their work as computational. Some participants said they were not sure if their experience counted toward our requirements. This self-doubt suggests that our sample excludes people who might be conducting interesting computational work but do not consider their projects computational. Furthermore, our sample is grounded in transformative fandom. There may be other communities outside of formal computing spaces that have similar features, and future work has the opportunity to explore at a much larger scale how people view their competency in computing. Finally, it is important to note many of our participants had intersectional identities. For example, being both a person of color and LGBTQ+. We did not ask participants to tease apart how and where these stereotypes were applicable to one aspect of their identity versus another.

\section{FINDINGS}

Our findings support and expand on previous findings about how computational labor is stereotyped $[7,18,32]$. Our participants were all involved in some significant computational project, and some were even pursuing careers in computing, or leading successful careers in computer or data science. Still, they described moments where they discounted or underplayed their own expertise. Participants who had become experts described moments throughout their education where they were frustrated or disappointed in the computer science curriculum they encountered. In contrast, participants described the opportunities they found through creative computational work within fandom and experiences they found elsewhere that mirrored those.

\subsection{Computer Science is not "Fun"}

When asked about their fandom-related computational projects, participants described complex, technical work that required expertise that they did not necessarily view as computation because it was something fun that they enjoyed. Even participants that have established careers in computer or data science described how at first they did not recognize what they did as computational. Participants still in school or pursuing other careers often struggled to identify if the work they did was "computer science enough." Whatever computer science was, it was not whatever they were doing. One participant who is now a data scientist described not really thinking about the websites and online archive that they had built as a teenager as real computational work:

"I'd done all this stuff, but I did not understand that I was doing actual grown-up things. To me it was just silly fanfic world." P11

Another participant, now working in software development, also said she did not recognize at the time that her fandom-related hobbies were also teaching her valuable computational skills, and that these skills could lead to a job:

"I didn't know a lot about the real world [when I was a teen]. I just thought it was for fun and you didn't work on something that was fun. To me, coding on Neopets was a game or it was a hobby. You don't do your hobby as a job." P3

Upon reflection, both participants were able to recognize that these experiences helped them learn computing skills in their teenage years. Another participant, currently working as a web 
Table 1: Participant Demographics

\begin{tabular}{|c|c|c|c|c|c|}
\hline ID & Gender Identity & Sexual Orientation & Race/Ethnicity & Education & Job Type \\
\hline 1 & Cisgender Woman & Lesbian & White & Graduate degree in videogame design & Software Developer \\
\hline 2 & Cisgender Woman & Bisexual & White & Student in videogame design & Student \\
\hline 3 & Cisgender Woman & Mostly Straight & White & Arts and technology degree & Software Developer \\
\hline 4 & Cisgender Woman & No Answer & White & Student in videogame design & Student \\
\hline 5 & Transgender Man & Gay & White & Student in videogame design & Student \\
\hline 6 & Cisgender Man & Gay & White & College graduate & Pharmacy Technician \\
\hline 7 & Non-Binary & Lesbian & White & Women and gender studies degree & Data Scientist \\
\hline 8 & Cisgender Woman & Bisexual & Black & Student in computer science & Student \\
\hline 9 & Cisgender Woman & Bisexual & White & Music degree & Sound Designer \\
\hline 10 & Non-Binary & No Answer & White & Graduate degree in library science & Data Scientist \\
\hline 11 & Non-Binary & Bisexual & White & Graduate degree in media studies & Data Scientist \\
\hline 12 & Undecided & Queer & White & $\mathrm{PhD}$ in computer science & Computer Scientist \\
\hline 13 & Transgender Man & Gay & Ashkenazi Jew & Web design degree & Web Designer \\
\hline 14 & Cisgender Woman & Bisexual & South Asian Indian & Student in theater & Student \\
\hline 15 & Assigned Female at Birth & Queer & Black & Partial college & Unspecified career \\
\hline 16 & Cisgender Woman & Asexual/Queer & Asian American & Computer science degree & Unemployed \\
\hline 17 & Cisgender Woman & Asexual & Portuguese Hispanic & Web design associate's & Web designer \\
\hline 18 & Gender Apathetic & Sexuality Apathetic & Asian American & Engineering degree & Works in STEM \\
\hline 19 & Cisgender Woman & Straight & Black & Video production degree & Video Producer \\
\hline 20 & Cisgender Woman & Bisexual & Chinese American & Graduate student in library science & Student \\
\hline 21 & Non-binary & Lesbian & White & Student in mechanical engineering & Student \\
\hline 22 & Genderqueer & Asexual & Korean & Arts degree & Instructional Designer \\
\hline
\end{tabular}

designer, explained that the dominant image of programming does not align with what most people in computer science actually do:

"Pop culture paints its own picture of programming. You look at stuff like 'Hackers' and 'War Games.' That's what it looks like. It's super narrow... When I started [making] custom code for [LiveJournal blogs], it never occurred to me that I was programming." P17

Computer science is much broader than our participants first conceptualized it. These three participants all found their way to CS-related fields through non-traditional career paths, with P17 specifically returning to school for a degree in web design after she could no longer afford to make ends meet as a hairdresser. She described realizing that all the programming she did to make people's fandom blogs look and function well was something she could turn into a career. What had started out as a fun and creative outlet turned into the career of P17's dreams.

Like P17, many participants first approached coding and computational projects as a creative outlet, with P3 specifically highlighting that because building websites was a hobby of hers as a teenager, she did not consider it a potential career path until much later in her life. In contrast to what they did for fun, participants described computing as something that was not enjoyable or creative-at least, as it had been presented to them through popular culture and educational settings. However, creativity stands out as a strong motivator for involving participants in computer science projects and even careers.

\subsection{Computer science is not creative}

Participants often struggled (either in the past or currently) to see where creative activities were also computational. The idea that creative and fun work is not associated with computer science acted as a barrier for participants seeing the work they were passionate about as computational. For example, P15 described making digital music through manipulating old sound chips, but thought they were bad with technology based on a frustrating experience in a computer science class. Despite this misconception, a few participants found their way to computing through educational programs that paired computing and creativity. Participants 2, 4, and 5 were all students in video game design that had learned to program as part of their curriculum.

For those participants, computer science became a gateway to new forms of creativity in fandom. For example, P5 felt the interactivity of video games gave depth to fan content they felt was missing from their previous creations:

"When I was writing fanfiction, it wasn't bad. But it just felt like something was missing. Even when I was doing a comic about [my fandom], I just felt like it would feel more complete if it had that immersion factor that a video game has-the interaction and the 
sound and just the way that you can portray action in a video game." (P5)

P5 described being nervous to learn to code at first. They emphasized that they enjoyed the "creative" elements of game design that involved storytelling and art, but grew to enjoy programming as well after taking a course on Unity that emphasized creativity, noting that "[Learning to code] in a creative and low risk context is what really helped me become less intimidated by it.". This participant describes experiences similar to $\mathrm{P} 2$ and $\mathrm{P} 4$, who also encountered programming in low-risk, creative environments where programming felt part of the creative process. Other participants have described creative projects as motivation for learning a computational skill, like P20 who learned to build a website to host a novel translation they were working on:

"I don't know if you're familiar with [Book Name], but it's the hot new thing out of China that everybody wants to read, but the only complete existing English translation [is only okay]. It's perfectly accessible, but there were a lot of things that I would've worded differently...I wanted to make a translation, but it's something I could not host on AO3...I spent a week editing [Wordpress themes], learning how to use plugins. Just all this [computational] stuff. I'm actually a very weak computational person. I think computational stuff stresses me out. Like, website stuff. I just don't get it, but I want it to work." P20

While P20 had taken two classes on computing, they did not remember any of the lessons from those classes and had to start virtually from the ground up in building their website. Despite considering their own skills in computing to be very weak, P20 successfully put together a custom website to host an independent project. Much of P20's self-doubt might be tied to how people selfassess their own competency in programming [14]. However, P20's drive to learn the skills needed to host their translation project points to the idea that creative projects can be a powerful motivator for learning computational skills. In talking about learning math, one participant described their frustration with having to learn skills divorced from the projects they wanted to use them with:

"I didn't want to do the things that I didn't find fun and interesting and I didn't see why I should have to because it was like I was going down a path that was really cool and if I needed to find something out to get further down that path, of course I would go learn it even if it was boring, you know?" (P11)

Another participant described a disconnect between learning computational skills independently for fandom projects and learning them in school. P13 did web design in fandom for custom blogs in the role-play community (a subgroup of fandom where people act out stories by assuming the roles of different characters). When he went to college for web design, he found certain elements lacking:

"When I was 18, I started taking courses at community college in web design... so that really helped me improve [my skills]...I wasn't the biggest fan of it, because it was mainly corporate marketing and very bland. I love the creativity of fandom and the familiarity of characters." P13
P13's dissatisfaction with their web design classes contrasts with the experiences of $\mathrm{P} 2,4$, and 5 who all encountered a positive integration of creativity and computation into each of their different videogame-focused programs. Our participants' different experiences show that the type of academic environment each participant learns in affects how they view computation and creativity as a whole, and whether or not a particular class fosters an environment of creativity greatly influenced how participants viewed computational labor in connection with creativity.

\subsection{Computer science is too hard for me}

Participants had expectations of what it means to be a competent computer scientist, or to work with computers competently, and those expectations shifted over time. Many participants saw computer science and coding as something daunting and too hard to learn without prior knowledge or experiences. For those participants who had such experience, these expectations largely came from their experiences with traditional computer science education. For example, one participant recounted how their first computer science class in high school seemed to be more helpful to students with a background in coding:

"I've taken two computer programming classes, one in high school, which was not very useful because it was really aimed towards people who already knew things about coding, I think. Or like my brain doesn't process it very well." P20

Previously, we highlighted how P20 learned programming as a tool to complete a creative project. Here, they express the idea that computer science is something a person needs to have the right brain for. This expectation did not come from nothing. Plenty of participants described situations where their formal learning experiences cultivated this expectation. Another participant mentioned that the classes they took in college created pressure by making students feel like they were not knowledgeable if they did not answer questions with a single correct answer:

"I taught myself statistics in order to do a job and now I'm employed as a data fucking scientist because [my college] classes sucked...I did not want to take them. I didn't want to be around them. I hated them and the reason I hated them was it felt like there was a single right answer. And if you did not already know how to get the right answer, then you were wrong." P11

However, participant attitudes toward learning computer science changed when they learned computer science in a setting that seemed most comfortable to them, whether it was learning how to code on their own through tutorials online or learning in classrooms with an atmosphere that allowed students to make mistakes. One participant who learned a lot of computing skills at summer camp compared that experience to taking a college computing course that had a more inclusive environment. They explained how the inclusive environment they were a part of made learning computer science a lot easier and more comfortable:

"[W]hen you're learning, you're in a vulnerable position where you have to ask for help. Sometimes there are people who are not the kindest when you ask for 
help. Namely men, because [they man-splain] and I didn't have to deal with it in that [computing] camp [the first time I attended]. I ended up taking that camp [again] and it was led by a male teacher and I dropped out because he was so condescending and all of my classmates were girls but the environment was so different because it wasn't led by women. It wasn't as encouraging. It wasn't as empowering." P14

Many participants held the preconception that becoming a knowledgeable and competent computer scientist is very difficult, or that it was simply not something they could achieve. However, participants also described turning points in their experiences with computing where they started to feel knowledgeable. For example one participant discussed their experience with learning coding in college and noted the difference between taking a class that they felt lost in versus another class that they enjoyed:

"[My first programming course was] notoriously [bad] for my major... And I had done no coding before, and I hated every minute of it...I couldn't check my intuition against it the way I could with physics...[Now, I am learning] Python because [I'm thinking of going into robotics]. I started to feel like I had some level of accomplishment, at least towards the end of the term when students would hit me up with questions." P21

Learning CS in fandom changed P17's life, moving from a deadend job to a thriving career, opening many doors for her. P17 explained how conventional spaces such as the traditional classroom setting are often crowded with white men, and very few women and people of color, and unconventional spaces are where you find more underrepresented groups in computing:

"If you want to broaden your pool for computing, you have to look in unconventional spaces. If you stay in the conventional space, you're going to get a lot of white dudes. It's going to be peppered with women and people of color, but it's mostly going to be white males... You have to look at unconventional spaces, you just have to." P17

Another thing P17 noted was that the digital space is traditional a "boys club" (P17) and if recruiters really wanted to change computer science education and industry to become more diverse, then they should start recruiting people from unconventional spaces. The idea of "paying it forward" is something that P17 valued as a means for involving other people from fandom in computer science, noting that it was the main reason she made her code freely available for others to use in their fandom blogs:

"I feel like I should pay that forward. If even one person starts grabbing my code and tweaking it and decides [they really like it and it changes their life], then I've paid forward what [Mary] did for me." P17

P17 does not expect the people in her fandom community (usually women and LGBTQ+ people) to find their way to computer science in a formal education space based on her own experiences. By making her code available to others, she hopes to broaden their participation in computing.

\section{DISCUSSION}

Our participants often thought that computer science was not fun or creative, and that it was too difficult unless they were the right "type" of person. These perceptions were enforced by educational experiences. However, we also heard how classroom experiences broke down these stereotypes, which means that educators and professionals can help. Prior work has shown that undoing stereotypes toward who a computer scientist is increases underrepresented groups' interest in computer science [7, 18]. However, we should also work to undo stereotypes of computational labor itself, and in doing so there may be a lesson from our participants who undervalued their own computational skills while also valuing a community they cared about as a space to play and learn.

Our findings suggest the importance of recognizing that stereotypes go beyond who can be a computer scientist and also extend to what "counts" as computer science. We saw many examples of what, in theory, is successful broader participation in computing by women, LGBTQ+ people, and people of color-if only they saw their work as computing. Therefore, we can focus recruitment efforts on multi-faceted creative projects. Our participants viewed computing as a means for accomplishing a larger goal, often tied to their fan community, and not a skill to learn on its own.

In prior work, we have seen how people in fan communities learned to code through legitimate peripheral participation while contributing to AO3 [12]. These developers, mostly women, felt they were in a supportive environment while learning to code for $\mathrm{AO} 3$ and even contrasted how AO3 felt safer than collaborative open source software projects. Our participants echoed similar sentiments, that fandom was a safe space to explore and play. How do we encourage this kind of environment in an academic setting? Prior work has emphasized teaching creative computational projects $[13,22]$. In addition to emphasizing creativity, we might also reach out to communities where underrepresented groups are already teaching and learning computing. We need to meet these groups where their passions are relevant: for example, organizations like Black Girl Gamers ${ }^{1}$.

Rather than focusing entirely on bringing people into traditional computing spaces, can we provide support-and importantly, legitimize-the computational labor that is already happening inside marginalized communities? Much like how individuals might not even recognize the need to seek out social support around stigmatized topics [10], some do not think they enjoy computing or recognize what they are doing as such, and so might not seek out further learning or professional opportunities. Many underrepresented groups might be participating in computing more than we thought, but perhaps beyond where we might think to look.

\section{CONCLUSION AND FUTURE WORK}

Our findings offer another dimension to consider in how stereotypes impact perceptions of computer science and how community drives a passion to learn. Future work should identify bridges between creativity and computational labor while also undoing restrictive ideas of what counts as computer science. Furthermore, we should continue to investigate communities where underrepresented groups are learning outside of formal education spaces.

\footnotetext{
${ }^{1}$ https://twitter.com/blackgirlgamers
} 


\section{ACKNOWLEDGEMENTS}

We would like to thank our participants for sharing their stories. We also would like to thank the members of the Internet Rules Lab (IRL) for their support throughout the research process. In particular, we would like to thank Mikhaila Friske and Blakeley Payne for providing close readings of early drafts. This work was funded by NSF award 1936741: Broadening Participation in Computing through Transforming Media and Technologies.

\section{REFERENCES}

[1] Amnah Alshahrani, Isla Ross, and Murray I Wood. 2018. Using social cognitive career theory to understand why students choose to study computer science. In Proceedings of the 2018 ACM conference on international computing education research. 205-214.

[2] Camille Bacon-Smith. 1992. Enterprising women: Television fandom and the creation of popular myth. University of Pennsylvania Press.

[3] Rachel A Bergstrom. 2019. Motion sickness as metaphor: engaging with diversity in STEM.

[4] Rebecca Black, Jonathan Alexander, Vicky Chen, and Jonathan Duarte. 2019 Representations of Autism in Online Harry Potter Fanfiction. Journal of Literacy Research 51, 1 (2019), 30-51.

[5] Virginia Braun and Victoria Clarke. 2006. Using thematic analysis in psychology Qualitative research in psychology 3, 2 (2006), 77-101.

[6] Coleen Carrigan. 2018. 'Different isn't free': Gender @ work in a digital world. Ethnography 19, 3 (2018), 336-359.

[7] Sapna Cheryan, Victoria C Plaut, Caitlin Handron, and Lauren Hudson. 2013. The stereotypical computer scientist: Gendered media representations as a barrier to inclusion for women. Sex roles 69, 1-2 (2013), 58-71.

[8] Mathilde Collain and Deborah Trytten. 2019. "You don't have to be a white male that was learning how to program since he was five": Computer Use and Interest from Childhood to a Computing Degree. In Proceedings of the 50th ACM Technical Symposium on Computer Science Education. 968-974.

[9] Francesca Coppa. 2011. An Editing Room of One's Own: Vidding as Women's Work. Camera Obscura: Feminism, Culture, and Media Studies 26, 2 (77) (2011), 123-130.

[10] Brianna Dym, Jed R Brubaker, Casey Fiesler, and Bryan Semaan. 2019. "Coming Out Okay": Community Narratives for LGBTQ Identity Recovery Work. Proceedings of the ACM on Human-Computer Interaction 3, CSCW (2019), 1-28.

[11] Casey Fiesler, Shannon Morrison, and Amy S Bruckman. 2016. An archive of their own: a case study of feminist HCI and values in design. In Proceedings of the 2016 CHI Conference on Human Factors in Computing Systems. 2574-2585.

[12] Casey Fiesler, Shannon Morrison, R Benjamin Shapiro, and Amy S Bruckman. 2017. Growing their own: Legitimate peripheral participation for computational learning in an online fandom community. In Proceedings of the 2017 ACM conference on computer supported cooperative work and social computing. 1375-1386.

[13] Jason Freeman, Brian Magerko, Tom McKlin, Mike Reilly, Justin Permar, Cameron Summers, and Eric Fruchter. 2014. Engaging underrepresented groups in high school introductory computing through computational remixing with EarSketch In Proceedings of the 45th ACM technical symposium on Computer science education. $85-90$.
[14] Jamie Gorson and Eleanor O'Rourke. 2020. Why do CS1 Students Think They're Bad at Programming? Investigating Self-efficacy and Self-assessments at Three Universities. In Proceedings of the 2020 ACM Conference on International Computing Education Research. 170-181.

[15] Bryce E Hughes. 2018. Coming out in STEM: Factors affecting retention of sexual minority STEM students. Science advances 4, 3 (2018), eaao6373.

[16] Amruth N Kumar. 2012. A study of stereotype threat in computer science. In Proceedings of the 17th ACM annual conference on Innovation and technology in computer science education. 273-278.

[17] Lynette Kvasny, KD Joshi, and Eileen Trauth. 2011. The influence of self-efficacy, gender stereotypes and the importance of it skills on college students' intentions to pursue IT careers. In Proceedings of the 2011 iConference. 508-513.

[18] Colleen M Lewis, Ruth E Anderson, and Ken Yasuhara. 2016. "I Don't Code All Day": Fitting in Computer Science When the Stereotypes Don't Fit. In Proceedings of the 2016 ACM conference on international computing education research. 23-32.

[19] Jacqueline Low. 2019. A pragmatic definition of the concept of theoretical saturation. Sociological Focus 52, 2 (2019), 131-139.

[20] Jane Margolis. 2010. Stuck in the shallow end: Education, race, and computing. MIT press.

[21] Jane Margolis and Allan Fisher. 2002. Unlocking the clubhouse: Women in computing. MIT press.

[22] Nick Montfort. 2016. Exploratory programming for the arts and humanities. MIT Press.

[23] Annemarie Navar-Gill and Mel Stanfill. 2018. "We Shouldn't Have to Trend to Make You Listen": Queer Fan Hashtag Campaigns as Production Interventions. fournal of Film and Video 70, 3-4 (2018), 85-100.

[24] Elizabeth Patitsas, Michelle Craig, and Steve Easterbrook. 2014. A historical examination of the social factors affecting female participation in computing. In Proceedings of the 2014 conference on Innovation \& technology in computer science education. 111-116.

[25] Christopher A Paul. 2018. The toxic meritocracy of video games: Why gaming culture is the worst. U of Minnesota Press.

[26] Amanda Phillips. 2020. Negg(at)ing the Game Studies Subject: An Affective History of the Field. Feminist Media Histories 6, 1 (2020), 12-36.

[27] Penny Rheingans, Erica D’Eramo, Crystal Diaz-Espinoza, and Danyelle Ireland. 2018. A model for increasing gender diversity in technology. In Proceedings of the 49th ACM Technical Symposium on Computer Science Education. 459-464.

[28] Irving Seidman. 2006. Interviewing as qualitative research: A guide for researchers in education and the social sciences. Teachers college press.

[29] Steven J Spencer, Christine Logel, and Paul G Davies. 2016. Stereotype threat. Annual review of psychology 67 (2016), 415-437.

[30] Kyle Thayer and Amy J Ko. 2017. Barriers faced by coding bootcamp students. In Proceedings of the 2017 ACM Conference on International Computing Education Research. 245-253.

[31] Heather K Tillberg and J McGrath Cohoon. 2005. Attracting women to the CS major. Frontiers: a journal of women studies (2005), 126-140.

[32] Eileen M Trauth, Curtis C Cain, Kshiti D Joshi, Lynette Kvasny, and Kayla M Booth. 2016. The influence of gender-ethnic intersectionality on gender stereotypes about IT skills and knowledge. ACM SIGMIS Database: the DATABASE for Advances in Information Systems 47, 3 (2016), 9-39.

[33] Jennifer Wang, Sepehr Hejazi Moghadam, and Juliet Tiffany-Morales. 2017. Social perceptions in computer science and implications for diverse students. In Proceedings of the 2017 ACM Conference on International Computing Education Research. 47-55. 